\title{
Identification of the Key Aroma Compounds in Dried Roots of Rubia cordifolia
}

\author{
Mitsuo Miyazawa* and Jyunichi Kawata \\ Department of Applied Chemistry, Faculty of Science and Engineering, Kinki University \\ (3-4-1 Kowakae, Higashiosaka-shi, Osaka 577-8502, JAPAN)
}

Edited by J. Sekiya, Kyoto Univ., and accepted August 30, 2005 (received for review June 13, 2005)

\begin{abstract}
The compositions of the essential oil from Rubiae Radix (roots of Rubia cordifolia, Rubiaceae) have been investigated by capillary GC and GC/MS. The important odoractive compounds were also detected in the oil using GC-Olfactometry (GC-O) and aroma extract dilution analysis (AEDA). As a result, 43 components, accounting for $91.5 \%$ of the total oil, were detected. The main components in the essential oil were mollugin $(19.6 \%)$, furomollugin (17.4\%), eugenol (12.7\%) and $(E)$-anethole (10.6\%). AEDA and GC-O showed that geraniol, eugenol and geranyl acetate were the most aroma-compounds.

Key words: Rubia cordifolia L., essential oil, gas chromatography-olfactometry, aroma extract dilution analysis, mollugin, furomollugin
\end{abstract}

\section{Introduction}

Rubiae Radix ('sensou' in Japanese) is the dried roots of Rubia cordifolia L. Rubiaceae. It has been long used as hematopoietic, anastaltic and dyestuff and for the treatment of hematemesis, hematuria and menoxenia in Japan and China. When the crude drug is decocted by hot water, characteristic odor is given off, which is sweet-floral odor and weak pungent-green odor. The genus Rubia is a source rich in anthraquinones. For example, many anthraquinones such as 1-hydroxy-2-methylanthraquinone and nordamnacanthal had been isolated from the roots of $R$. cordifolia (1-5). Naphthohydroquinones such as mollugin and furomollugin had been also isolated from the roots (6-10). However, to the best of our knowledge, there is no report on the volatile components for the Chinese crude drug.

Gas chromatography-olfactometry (GC-O) is the most valuable technique used to identify the key aroma compounds in foods. There are various methods for the screening odor-active compounds. One of the most frequently used methods is aroma extract dilution analysis (AEDA) (11).

In this paper, the volatile constituents of $R$. cordifolia roots were investigated by GC and GC/MS. The important odor-active compounds were detected in the oil using GC-O and AEDA.

\section{Experimental}

\subsection{Plant}

Commercially available air-dried roots (Chinese Rubiae Radix) of $R$. cordifolia (Takasago Yakugyou Co. Ltd, Osaka) were used.

\section{$2 \cdot 2$ Isolation of the Essential Oil}

One hundred grams of dry coarsely powdered plant material were hydrodistilled with a Likens-Nickersontype apparatus using ethyl ether to yield $0.027 \%$ of yel-

\footnotetext{
*Correspondence to: Mitsuo MryaZAWA, Department of Applied Chemistry, Faculty of Science and Engineering, Kinki University, 3-4-1

Kowakae, Higashiosaka-shi, Osaka 577-8502, JAPAN

E-mail: miyazawa@apch.kindai.ac.jp
} 
low oil. The obtained oil was dried over anhydrous sodium sulfate prior to analyses.

\subsection{Gas Chromatography-Olfactometry and AEDA}

GC was carried out using Agilent Technologies $6890 \mathrm{~N}$, fitted with a non-polar capillary column HP-5 (J\&W Scientific; $30 \mathrm{~m} \times 0.32 \mathrm{~mm}$, film thickness 0.25 $\mu \mathrm{m})$. The oven temperature was programmed from 40 $240^{\circ} \mathrm{C}$ at a rate of $4^{\circ} \mathrm{C} / \mathrm{min}$ and held at $240^{\circ} \mathrm{C}$ for $5 \mathrm{~min}$. The injector temperature was $240^{\circ} \mathrm{C}$. The flow rate of the carrier gas $(\mathrm{He})$ was $1.800 \mathrm{~mL} / \mathrm{min}$. The Chemstation software acquired two channel signals simultaneously, one channel for the flame ionization detector (FID), and other channel from the olfactometer signal board. A single sniffer, the author, recorded the aroma character manually. The flavor dilution (FD) factor of the odorants in the essential oil was determined by aroma extract dilution analysis (AEDA). The highest sample concentration $(1 \mathrm{mg} / \mathrm{ml})$ was assigned a FD-factor of 1 . The oil was stepwise diluted $(1+1, \mathrm{v} / \mathrm{v})$ by addition of diethyl ether. Aliquots of the dilutions were then analyzed by GC-O. The results are expressed as
FD-factor. An odorant with high FD-factor can be judged as an important contributor to the characteristic flavor.

\subsection{Gas Chromatography-Mass Spectrome- try (GC-MS)}

The GC-MS analysis was carried out using a Hewlett Packard model 5890 GC with a Hewlett Packard 5972A MS. The capillary column was a DB-5MS (J\&W Scientific; $30 \mathrm{~m} \times 0.25 \mathrm{~mm}$, film thickness $0.25 \mu \mathrm{m}$ ). The oven temperature was programmed from $60-240^{\circ} \mathrm{C}$ at a rate of $2^{\circ} \mathrm{C} / \mathrm{min}$ and held at $240^{\circ} \mathrm{C}$ for $5 \mathrm{~min}$. The flow rate of the carrier gas $(\mathrm{He})$ was $0.679 \mathrm{~mL} / \mathrm{min}$. The detector interface temperature was set at $280^{\circ} \mathrm{C}$, with the actual temperature in the MS source reaching approximately $180^{\circ} \mathrm{C}$. The ionization voltage was 70 $\mathrm{eV}$.

\subsection{Identification of Constituents}

The components of the essential oils were identified by direct comparison of their mass spectral pattern and retention index (RI) with those published in the literature $(9,12,13)$.

Table 1 Compounds of Essential Oil from Roots of Rubia cordifolia.

\begin{tabular}{rrlccclc}
\hline No & RI & \multicolumn{1}{c}{ Compound } & peak area (\%) & No & RI & \multicolumn{1}{c}{ Compound } & peak area (\%) \\
\hline 1 & 860 & furfural & $\operatorname{tr}$ & 32 & 1397 & methyl eugenol & 1.2 \\
2 & 871 & $(2 E)$-hexenal & $\operatorname{tr}$ & 35 & 1444 & geranyl acetone & 0.8 \\
3 & 948 & benzaldehyde & 0.1 & 36 & 1475 & ar-curcumene & 0.2 \\
4 & 1033 & benzene acetaldehyde & 0.2 & 37 & 1479 & $\beta$-selinene & 0.3 \\
5 & 1090 & cis-linalool oxide & $\operatorname{tr}$ & 38 & 1492 & 2 -tetradecanone & 1.2 \\
6 & 1147 & $(2 E$-nonenal & $\operatorname{tr}$ & 39 & 1503 & acenaphthene & 1.5 \\
7 & 1168 & borneol & 1.6 & 40 & 1511 & $\delta$-amorphene & 0.3 \\
8 & 1175 & menthol & 2.7 & 41 & 1514 & myristicin & 1.0 \\
9 & 1192 & $\alpha$-terpineol & 1.9 & 45 & 1571 & caryophyllene oxide & 0.4 \\
10 & 1195 & estragenole & $\operatorname{tr}$ & 46 & 1611 & dill apiole & 0.5 \\
14 & 1234 & pulegone & 0.6 & 47 & 1618 & 1 -epi-cubenol & 0.2 \\
15 & 1250 & $p$-anisaldehyde + piperitone & 1.2 & 48 & 1630 & hinesol & 0.2 \\
16 & 1253 & geraniol & $\operatorname{tr}$ & 49 & 1633 & cubenol & 0.1 \\
18 & 1268 & (E)-cinnamaldehyde & 0.8 & 50 & 1645 & $\beta$-eudesmol & 0.8 \\
19 & 1285 & (E)-anethole & 10.6 & 51 & 1657 & ar-turmerone & 0.6 \\
20 & 1291 & 2-undecanone & 0.8 & 52 & 1760 & phenanthrene & 0.1 \\
22 & 1297 & carvacrol & 0.3 & 54 & 1923 & methyl palmitate & 0.2 \\
23 & 1305 & 4-vinyl- $o$-guaiacol & 0.2 & 55 & 2024 & 4 -tert-butyl-2-phenyl phenol & 9.9 \\
27 & 1351 & eugenol & 12.7 & 56 & 2080 & furomollugin & 17.4 \\
28 & 1355 & $\gamma$-nonalactone & 0.2 & 59 & 2122 & linoleic acid & 0.2 \\
29 & 1369 & $\alpha$-yalangene & 0.2 & 62 & 2237 & mollugin & 19.6 \\
30 & 1373 & (E)- $\beta$-damascenone & 0.5 & & & & \\
31 & 1385 & geranyl acetate & $\operatorname{tr}$ & & & total & 91.5 \\
\hline RI: Retention & Index; tr: trace $<0.1$ & & & & &
\end{tabular}


Table 2 Most Odor-active Compounds in Essential Oil from Roots of Rubia cordifolia.

\begin{tabular}{clccl}
\hline No & \multicolumn{1}{c}{ Aroma quality } & RI & FD-factor & Aroma Compound \\
\hline 1 & green-fruity, pungent & 871 & 4 & $(2 E)$-hexenal \\
2 & sweet-woody & 1090 & 4 & cis-linalool oxide \\
3 & fatty-orrisy & 1147 & 1 & $(2 E)$-nonenal \\
4 & pungent & 1153 & 1 & unknown \\
5 & mild and sweet, floral & 1253 & 64 & geraniol \\
6 & warm-spicy & 1356 & 32 & eugenol \\
7 & sweet, fruity-floral & 1385 & 16 & geranyl acetate \\
\hline
\end{tabular}

\section{Results and Discussion}

The essential oil from Rubiae Radix was analyzed on $\mathrm{GC}$ and GC/MS. The percentage composition and modes of identification of the oil components are listed in Table 1. In the oil, 43 components, accounting for $91.5 \%$ of the total oil, were identified. The main components were mollugin (19.6\%), furomollugin (17.4\%), eugenol $(12.7 \%),(E)$-anethole $(10.6 \%)$, 4-tert-butyl-2phenyl phenol (9.9\%), menthol (2.7\%), $\alpha$-terpineol $(1.9 \%)$. This oil was interesting because it contained large amounts of mollugin and furomollugin. The two naphthohydroquinones were isolated from roots, however there is no report on the identification of two naphthoquinones in any natural essential oil. Because the compounds suppressed the secretion of hepatitis B surface antigen in human hepatoma cells by (10), it is possible that essential oil inhibits chronic and acute hepatitis.

The results of the GC-O and AEDA studies are given in Table 2. Geraniol, eugenol, geranyl acetate, $(2 E)$ hexenal and cis-linalool oxide were the most aromacompounds in the oil (FD factor $>4$ ). Geraniol, eugenol, geranyl acetate cis-linalool oxide and green note such as $(2 E)$-hexenal, $(2 E)$-nonenal may contribute to sweet-flower note, characteristic odor of the oil.

\section{Acknowledgment}

This work was supported by "High-Tech Research Center" project for Private Universities: matching fund subsidy from Ministry of Education, Culture, Sports, Science and Technology, Japan (2004-2008).

\section{References}

1. V.V.S. MURTI, T.R.SESHADRI and S. SIVAKUMARAN,
Anthraquinones of Rubia cordifolia, Phytochemistry, Vol. 11, 1524 (1972).

2. A.M. TESSIER, P. DELAVEAU and B. CHAMPION, New anthraquinones in Rubia cordifolia root, Planta Med., Vol. 41, 337-343 (1981).

3. C. DOSSEH, A.M. TESSIER and P. DELAVEAU, Rubia cordifolia roots II. New quinones, Planta Med., Vol. 43, 141-147 (1981).

4. A.M. VIDAL-TESSIER, P. DELAVEAU and B. CHAMPION, New anthraquinones of Rubia cordifolia L. Roots, Ann. Pharm. Fr., Vol. 45, 261-267 (1987).

5. E. OKUYAMA, K. SATO and K. YOSHIHIRA, 2-Ethoxycarbonyl-1-hydroxy Anthraquinone from Rubia alkane, Phytochemistry, Vol. 29, 3973-3974 (1990).

6. A.G. GONZALEZ, R.J. CARDONA, J.M. MEDINA and L.F. RODRUQUEZ, Rubiaceae Chemistry I. Quinone Components of Putoria calabrica, Anal. Quim. (1968-1979), Vol. 70, 858859 (1974).

7. A.G. GONZALEZ, J.T. BARROSO, R.J. CARDONA, J.M. MEDINA and L.F. RODRUQUEZ, Chemistry of the Rubiaceae II. Components of Putoria calabrica Perss, Anal. Quim. (19681979), Vol. 73, 538-545 (1977).

8. Y.F. QIAO, S.K. WANG, L.J. WU, X. LI and T.R. ZHU, Antibacterial Constituents from the Roots of Rubia cordifolia L., Yаохие Хиеbаo, Vol. 25, 834-839 (1990).

9. H. ITOKAWA, Y. IAO and K. TAKEYA, 6-Methoxygeniposidic Acid, and Iridoid Glycoside from Rubia cordifolia, Phytochemistry, Vol. 30, 637-640 (1991).

10. L.K. HO, M.J. DON, H.C. CHEN, S.F. YEH and J.M. CHEN, Inhibition of Hepatitis B Surface Antigen Secretion on Human Hepatoma Cells. Components from Rubia cordifolia, J. Nat. Prod., Vol. 59, 330-333 (1996).

11. W. GROSCH, Evaluation of the Key Odorants of Foods by Dilution Experiments, Aroma Models and Omission, Chem. Senses., Vol. 26, 533-545 (2001).

12. R.P. ADAMS, Identification of Essential Oil Components by Gas Chromatography/ Quadropole Mass Spectroscopy, Allured Publ. Corp., Carol Stream, IL, USA (2001).

13. H. SCHILDKNECHT and F. STRAUB, Structure and Synthesis of Furomollugin from Rhizomes of Galium mollugo L. (Rubiaceae), Liebigs Ann. Chem., Vol. 10, 1772-1776 (1976). 